\title{
Review of: "Saphenous vein valve assessment utilizing upright CT to potentially improve graft assessment for bypass surgery"
}

Hugh Paterson, Paul Bannon

Potential competing interests: The author(s) declared that no potential competing interests exist.

Hugh S. Paterson FRACS ${ }^{1}$, Paul G Bannon FRACS PhD ${ }^{1,2}$.

1. Central Clinical School, University of Sydney. NSW. Australia.

2. Department of Cardiothoracic Surgery, Royal Prince Alfred Hospital, Camperdown. NSW.

The importance of saphenous vein valves (SVVs) in grafts for arterial bypass.

Imaging of SVVs.

In the June issue of Scientific Reports, Nakahara et al reported on the identification of saphenous vein valves in the thigh (1). A prototype vertical computerised tomography (CT) scanner with a wide scan range and high spatial resolution was used to identify the location and numbers of the SVVs without the use of contrast in volunteers in a standing position. The SVVs were identified by the localized dilatations (valve sinuses) in the saphenous veins (SVs) rather by direct detection of the valve leaflets. This limitation might underestimate the number of SVVs. The scans were repeated in those volunteers in a supine position using an equivalent horizontal scanner which proved less able to identify the SVVs in the absence of the increased lower limb venous pressure provided by gravity when standing.

The accuracy of the vertical scanner was validated by scanning cadaveric lower limbs and then filleting the entire length of the saphenous veins to confirm the numbers and locations of the SVVs macroscopically. This is the only report of identification of SVVs by vertical CT scanning and without the use of contrast, it is deemed relatively non-invasive. As the clinical application of vertical CT scanning is limited, this tool currently seems reserved for research into various aspects of phlebology. The option to increase the venous pressure with a venous tourniquet around the upper thigh and obtain equivalent accuracy in a horizontal scanner to that in the vertical scanner was not tested and remains unknown. This would restrict imaging of the upper portion of the SV in which the distribution of SVVs tends to be highest.

The findings of this study (4 SVVs per thigh, IQR 3-5) are consistent with those of other researchers who have assessed the number of SVVs in cadavers with averages varying from 3.5 to 5.2 SSVs per thigh (2). Contrast venography has been shown to underestimate the number of SVVs (3) and ultrasound detection of SVVs (4) has not been validated against macroscopic identification. This might relate to a perceived 
absence of clinical application.

Clinical application.

The paucity of reports on the numbers and locations of SVVs reflects the limited clinical application rather than the importance of this information. The phenomenon of accelerated atherosclerosis is commonly apparent in SV coronary bypass grafts after seven years following implantation. This atherosclerosis occurs more severely at the SVV sites (5) (Figure 1.) and suggests that the use of segments of SV free of SVVs might improve graft durability. However, with four SVVs in the $35 \mathrm{~cm}$ segment of the SV from the saphenofemoral junction to the knee, a SVV free segment will be of insufficient length for use in standard arterial bypass surgery. A $35 \mathrm{~cm}$ segment is usually harvested for coronary bypass surgery when the SV is used to revascularise both the circumflex and right coronary territories with aorto-coronary grafts. These grafts are usually a minimum of $12 \mathrm{~cm}$ in length. Although the probability of an SV graft being free of SVVs is low, there is likely benefit in minimizing the number of SVVs in grafts where possible.

The use of valveless SV grafts to revascularize the circumflex coronary territory as part of a composite graft configuration from the left internal mammary artery has been reported (6). The identification of the valveless segment of SV was performed intra-operatively by retrograde cannulation and pressurization of the vein after harvesting. To obtain a short segment of valveless SV without preharvest imaging to identify SVVs, it is necessary to harvest twice the length of the SV required for the graft to ensure an adequate length of valveless SV. With prior knowledge of SVV locations, harvesting of the correct length of SV known to be free of SVVs can be performed.

Composite coronary bypass grafts with the SV graft inflow from the left internal mammary artery have shown excellent mid-term patency rates of the SV segments in a randomized trial and observational studies (7). These findings are likely to increase the use of composite graft configurations that allow use of short SV segments. The use of short segments of SV has also been reported with other composite coronary bypass graft configurations where the selection of valveless segments of saphenous veins was possible (8). Summary.

This contribution by Nakahara et al has expanded the information available regarding the number and distribution of SVVs. Coronary bypass surgical techniques continue to evolve and this information is timely and useful to surgeons seeking new methods to improve outcomes.

\section{References}

1. Nakahara T, Yamada M, Yokoyama Y, Yamada Y, Narita K, Imanishi N, Yamazaki M, Shimizu H, Narula J, Jinzaki M. Saphenous vein valve assessment utilizing upright CT to potentially improve graft assessment for bypass surgery. Sci Rep. 2021 Jun 2;11(1):11602. doi: 10.1038/s41598-021-90998-7.

2.Portugal, I. B., Ribeiro Ide, L., Sousa-Rodrigues, C. F., Monte-Bispo, R. F. \& Rocha, A. C. Distribution of saphenous vein valves and its practical importance. Rev. Bras. Cir. Cardiovasc. 29, 564-568.

https://doi.org/10.5935/1678-9741.20140038 (2014).

3. Shah DM, Chang BB, Leopold PW, Corson JD, Leather RP, Karmody AM. The anatomy of the greater 
saphenous venous system. J Vasc Surg. 1986 Feb;3(2):273-83.

4. Necas M. Duplex ultrasound in the assessment of lower extremity venous insufficiency. Australas J Ultrasound Med. 2010 Nov;13(4):37-45. doi: 10.1002/j.2205-0140.2010.tb00178.x.

5. Mills NL, Everson CT. Vein graft failure. Curr Opin Cardiol. 1995 Nov;10(6):562-8. doi:

10.1097/00001573-199511000-00003.

6. Mayorchak Y, Paterson H, Ryan JB, Byth K, Robinson LM, Kovoor P, Denniss AR. Mammary artery to saphenous vein composite T grafts for coronary artery bypass: late follow-up. J Cardiovasc Surg (Torino). 2013 Aug;54(4):531-6.

7. Caliskan E, de Souza DR, Böning A, Liakopoulos OJ, Choi YH, Pepper J, Gibson CM, Perrault LP, Wolf RK, Kim KB, Emmert MY. Saphenous vein grafts in contemporary coronary artery bypass graft surgery. Nat Rev Cardiol. 2020 Mar;17(3):155-169. doi: 10.1038/s41569-019-0249-3

8. Paterson HS, Thakkar J, Byth K, Denniss AR. Saphenous vein to internal mammary artery end-to-end composite grafts for coronary artery bypass. Late follow-up. Heart Lung Circ. 2015 Feb;24(2):200-5. doi: 10.1016/j.hlc.2014.09.014.

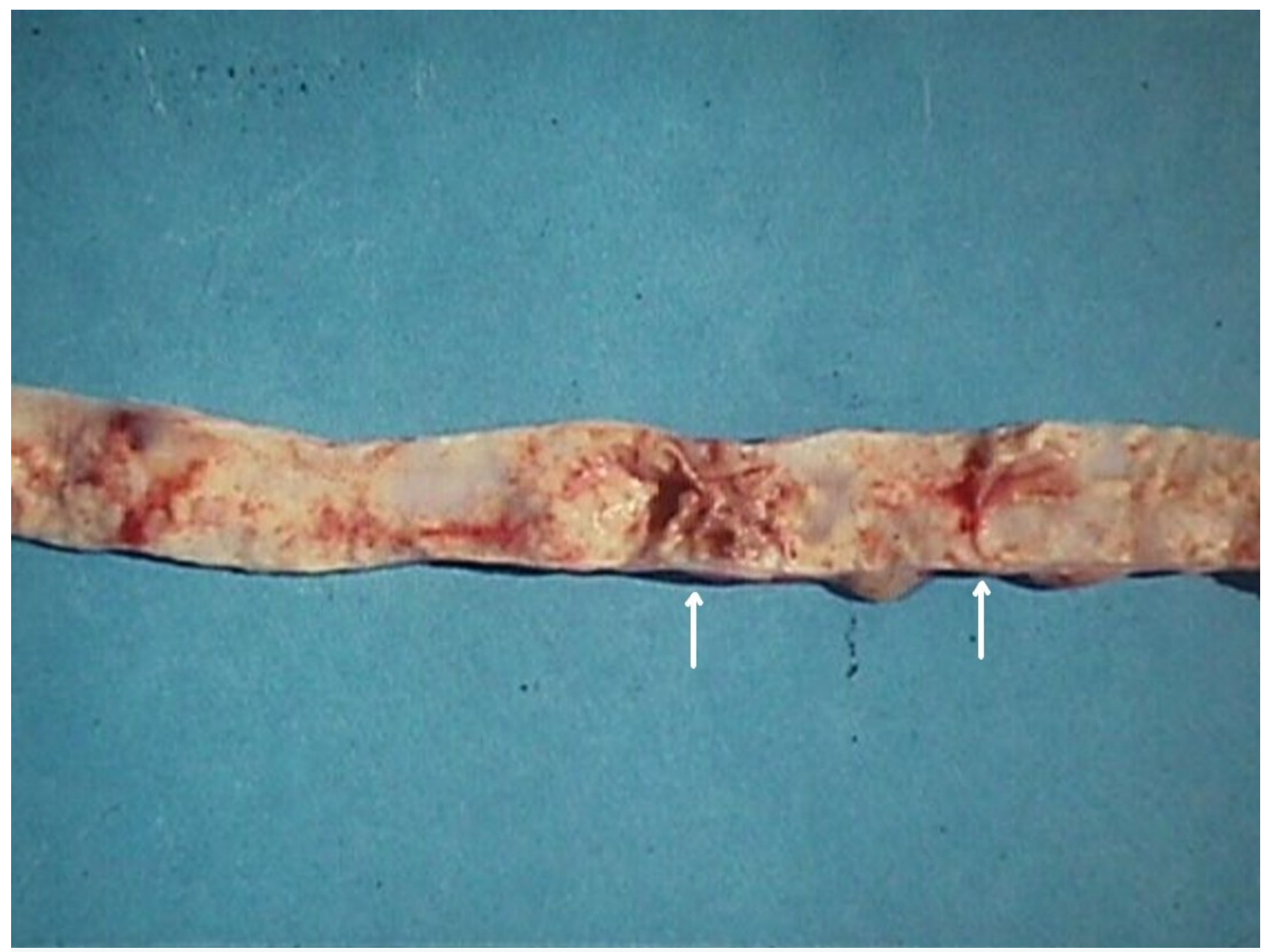

Finure 1 . Fiaht vear old sanhennus vein araft for cornnarv hvnacs. The diseaced araft hac heen exnlanted and filleted 
longitudinally to demonstrate the atheromatous disease. Arrows indicate sites of saphenous vein valves where the atheromatous disease appears most severe. 